Int. J. Dev. Biol. 52: 535-544 (2008)

doi: $10.1387 / \mathrm{ijdb} .072549 \mathrm{dd}$

\title{
Ultrastructural analysis of egg membrane abnormalities in post-ovulatory aged eggs
}

\author{
DIANE T. DALO ${ }^{1}$, J. MICHAEL MCCAFFERY² and JANICE P. EVANS ${ }^{1, *}$ \\ ${ }^{1}$ Department of Biochemistry and Molecular Biology, Division of Reproductive Biology, Bloomberg School of Public Health and \\ ${ }^{2}$ The Integrated Imaging Center, Johns Hopkins University, Baltimore, Maryland, USA
}

\begin{abstract}
Microscopic analyses of mammalian gamete ultrastructure have provided among the most seminal insights into fertilization. Here we present a summary of ultrastructural studies of mammalian fertilization, together with a review of the effects of post-ovulatory aging in eggs, and our own results using scanning electron microscopy to examine the effects of post-ovulatory aging on the egg membrane topography. Our previous work detected two abnormalities in egg membrane function in aged eggs: aged eggs appeared to be less able to support sperm-egg membrane interaction, thus rendering the eggs less fertilizable, and aged eggs appear to have a reduced ability to prevent polyspermy at the level of the egg membrane, i.e., to establish a membrane block to polyspermy. In the work presented here, we tested the suitability of both environmental (ESEM) and low-vacuum (LVSEM) modes of the FEI Quanta 200 Environmental Scanning Electron Microscope to study mammalian gametes. While ESEM mode was not sufficient under the conditions we used to observe fine cell surface details, the LVSEM mode proved to be an excellent way to view egg membrane topography. Unfertilized aged eggs have an abnormally distended amicrovillar region over the meiotic spindle, and fertilized aged eggs had three different abnormalities detected, from reduced sperm-induced membrane remodeling to abnormal sperm-induced membrane remodeling and membrane blebbing. Combining these insights of egg membrane function and topography with others in the field of post-ovulatory aging, we have expanded insights into why fertilization at increased times after ovulation is associated with poor reproductive outcomes.
\end{abstract}

KEY WORDS: fertilization, post-ovulatory aging, scanning electron microscopy, ICSI

\section{Introduction}

Gamete biology has a rich and wonderful history. Studies of gametes have yielded some fascinating findings that have provided insights into fundamental issues in cell biology, such as cell cycle regulation through studies of the egg-to-embryo transition in frogs and sea urchins (Murray and Hunt, 1993) and the discovery of guanylyl cyclases coming from fundamental studies of how sea urchin sperm were attracted to eggs (this issue and Hardman and Gilman, 2007). Studies of gametes have their own direct significance as well, with growing interest in reproductive health issues, such as infertility, advanced maternal age, contraception, and the effects of the environment on reproductive function. A distinctive part of gamete biology history is the microscopic analysis of mammalian gamete ultrastructure, which has provided some of the most seminal insights into fertilization. Here we review some of these data, and then apply this knowledge base to the issue of post-ovulatory aging, the cellular aging of the egg brought about by increased residence time in the oviduct following ovulation. Post-ovulatory aging has been a research area of interest for many decades, and studies of post-ovulatory aged eggs have gained extra significance with the advent of assisted reproductive techniques, particularly with the use of techniques involving reinsemination of eggs that had failed to fertilize with their first

\footnotetext{
Abbreviations used in this paper: AMV, amicrovillar; CG, cortical granule; CPD, critical-point drying; EM, electron microscopy (or microscope); ESEM, environmental scanning electron microscopy; HMDS, hexamethyldisilazane; ICSI, intracytoplasmic sperm injection; IVF, in vitro fertilization; LVSEM, low vacuum scanning electron microscopy; MV, microvillar; SEM, scanning electron microscopy; TEM, transmission electron microscopy; $\mathrm{ZP}$, zona pellucida.
}

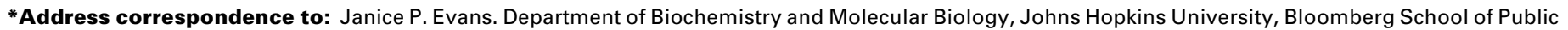
Health, Room W3606, 615 N. Wolfe St., Johns Hopkins University, Baltimore, MD 21205. Fax: +1-410-614-2356. e-mail: jpevans@jhsph.edu
} 
exposure to sperm by conventional in vitro fertilization (IVF). Reproductive success decreases with increasing time after ovulation, with problems such as decreased litter size, low pregnancy rates, and an increased risk of spontaneous abortion in humans (Blandau and Jordan, 1941, Blandau and Young, 1939, Gray et al., 1995, Guerrero and Lanctot, 1970, Guerrero and Rojas, 1975, Tarin et al., 2000, Wilcox et al., 1998). We will first present a summary of pertinent studies characterizing the ultrastructure of male and female gametes and of sperm incorporation into eggs, which then set the stage for the scanning electron microscopy studies of egg membrane membrane topography performed here, with a focus on abnormalities in egg membrane function in postovulatory aged eggs.

\section{Summary of key ultrastructural findings related to mammalian fertilization}

There is a distinct asymmetry in mammalian eggs, despite the simple outward appearance that these cells have. The meiotic spindle, arrested in metaphase II in most species (except in dogs and wolves, in which meiotic arrest is in metaphase I), is located eccentrically, near the cortical region of the egg. In metaphase II rodent eggs, there is additional polarity in the membrane surface and underlying cortex - the region of the cortex overlying the spindle is devoid of microvilli and is heavily enriched with F-actin (Longo and Chen, 1985, von Weymarn et al., 1980). The rest of the egg surface is characterized by dense microvilli, called the microvillar region. This polarity in the mature egg develops during oocyte maturation. The surface of pre-ovulatory prophase I oocytes in rodents and in humans is characterized by uniformly distributed microvilli (Sathananthan, 1994). As the oocyte progresses from prophase I arrest into meiosis I, the meiotic spindle forms in the central position (where the germinal vesicle was localized), and then migrates to a more peripheral location, such that the spindle is now positioned for the asymmetric cytokinesis that occurs with completion of meiosis I. In rodent eggs, this maturation-associated migration of oocyte chromatin from its central position to the egg cortex is accompanied by the loss of microvilli on the surface overlying the meiotic spindle and with an accumulation of F- actin (Longo and Chen, 1985, von Weymarn et al., 1980).

Electron microscopy studies in several species provide evidence that sperm binding and fusion with the egg plasma membrane appears to be facilitated by the microvilli on the egg (Yanagimachi and Noda, 1970; Yanagimachi, 1978; Shalgi and Phillips, 1980; Phillips and Shalgi, 1982; Talbot and Chacon, 1982). Thus, the asymmetry in surface topography translates to a distinct region for rodent sperm-egg interactions; sperm bind and fuse with the microvillar domain, but almost never in the amicrovillar domain.

After sperm penetration, a number of interesting changes occur, as the sperm induces remodeling of the egg surface and underlying cortex. SEM studies of eggs of a variety of species (e.g., mouse, hamster, rat, rabbit) show that the egg membrane surface becomes devoid of microvilli over the region of sperm entry, and this amicrovillar patch then develops $\sim 1.5-2.5 \mathrm{hr}$ postinsemination into what is called the fertilization cone, or incorporation cone, which is a amicrovillar protrusion over the decondensing sperm head (Phillips and Shalgi, 1982, Shalgi and
Kraicer, 1978, Shalgi and Phillips, 1980). Interestingly, the development of this sperm-associated amicrovillar domain and fertilization cone occurs even in eggs that do not develop a spindleassociated amicrovillar domain during oocyte maturation. In other words, while the formation of an amicrovillar domain over the metaphase II spindle does not occur in human and other nonrodent eggs, the formation of an amicrovillar patch over the sperm chromatin does occur following fertilization (Lopata et al., 1980). Later, the sperm tail is incorporated into the egg cytoplasm in the eggs of most species. Incorporation of the sperm tail has been documented by SEM in hamster, rat, and mouse. This appears to occur through a process progressing from the proximal end to the distal end of the tail in a "zipperlike" fashion (Szollosi, 1965, Szollosi and Hunter, 1973). Sperm tail interaction with the egg microvilli has been characterized as having distinct edges of "protuberances" from beneath the egg microvillar surface (as described in Phillips and Shalgi, 1982), and the engulfed sperm tail fuses at multiple sites along the egg microvillar surface (Shalgi and Phillips, 1980, Simerly et al., 1993). There are a few species in which sperm tail incorporation does not occur; the tails of the sperm in hamster and field vole often break off from the heads during fusion with the egg membrane, rather than the tails becoming incorporated into the egg cytoplasm (Austin and Braden, 1956).

\section{Post-ovulatory aging}

\section{Clinical implications for studies of post-ovulatory aging}

Increased rates of chromosomal abnormalities and aneuploidy in the female gamete contribute to the advanced chronological maternal age-associated decline in reproductive success. Similarly, cellular aging of the egg following ovulation that occurs with delayed conception can also result in compromised reproductive success, such as early pregnancy loss or miscarriage (Blandau and Jordan, 1941, Blandau and Young, 1939, Gray et al., 1995, Guerrero and Lanctot, 1970, Guerrero and Rojas, 1975, Tarin et al., 2000, Wilcox et al., 1998). A prospective study found that women who conceived at later times postovulation exhibited considerably higher rates of pregnancy loss than in those women who conceived much closer to the time of ovulation (Wilcox et al., 1998); the eggs fertilized at later times after ovulation would have experienced in vivo post-ovulatory aging. In addition to these cases with naturally-occurring conception in vivo, the "fertilizable lifespan" of eggs post-ovulation is an important consideration for the success of assisted reproductive technologies, such as IVF and intracytoplasmic sperm injection (ICSI) in infertility clinics. This may be an issue in cases where eggs remain in culture media for a period of time after collection and prior to IVF or ICSI, or in cases where «rescue ICSI» is performed following failure of IVF (e.g., Yuzpe et al., 2000). Normal "fertilizability" of an ovulated egg is likely to be less than 24 hours, and changes associated with postovulatory aging either in vivo or in vitro account for a specific and limited window of opportunity for successful in vivoconception or for assisted conception methods (Ducibella, 1998).

\section{Intracellular $\mathrm{Ca}^{2+}$ in post-ovulatory aged eggs}

The fertilizing sperm triggers changes in intracellular $\mathrm{Ca}^{2+}$ concentrations in the egg. In mammalian eggs, the increase in 
cytosolic $\mathrm{Ca}^{2+}$ concentrations occur in the form of transients, also called oscillations. These transients last for several hours in early embryonic development, and have distinct characteristics in frequency and amplitude; the characteristics of the calcium signals as well as the combined total calcium input affect the execution of a normal program of embryonic development (Ducibella et al., 2006, Malcuit et al., 2006).

Several abnormalities in the $\mathrm{Ca}^{2+}$ transients in post-ovulatory aged eggs have been reported. Decreased rates of $\mathrm{Ca}^{2+}$ concentration increase have been observed in aged mouse eggs activated by fertilization or by $\mathrm{IP}_{3}$ injection (Igarashi et al., 1997, Jones and Whittingham, 1996, Takahashi et al., 2000), and it has also been reported that aged mouse eggs exhibit increased frequencies of fertilization-induced $\mathrm{Ca}^{2+}$ transients and increased duration of individual $\mathrm{Ca}^{2+}$ transients, effectively causing the calcium signal to lose its oscillatory nature (Igarashi et al., 1997). These abnormal patterns of $\mathrm{Ca}^{2+}$ release in aged eggs may be due to decreased $\mathrm{Ca}^{2+}$ stores (Jones and Whittingham, 1996, Takahashi et al., 2000). Abnormal patterns of $\mathrm{Ca}^{2+}$ release may also contribute to reproductive failures in aged eggs. Activation of eggs parthenogentically by injection with an extract of soluble sperm proteins (including the sperm $\mathrm{Ca}^{2+}$ release activity associated with PLC $\zeta$ ) results in DNA and cytoplasmic fragmentation in in vitroaged eggs, rather than the activation of embryonic development observed when young eggs are injected with this sperm extract (Gordo et al., 2002, Gordo et al., 2000). A decrease in endoplasmic reticulum calcium stores due to aging may be the origin of abnormal oscillation patterns observed in post-ovulatory aged fertilized eggs (Fissore et al., 2002, Takahashi et al., 2000).

\section{Cortical and cytoskeletal abnormalities in post-ovulatory aged eggs}

Two different types of disruptions of the normal cortical organization have been observed in post-ovulatory aged mouse eggs. Unfertilized young rodent eggs have an actin-rich cap in the cortical region overlying the metaphase II spindle (Longo, 1985). Some aged eggs exhibited no actin cap over the spindle (Webb et al., 1986, Wortzman and Evans, 2005), while other eggs can have an extensive actin-rich protrusion over the spindle (Wortzman and Evans, 2005). TEM studies have also shown that in aged mouse eggs cortical granules migrate away from the membrane and into central region of the egg, appearing to lose their anchorage in the cortex (Szollosi, 1971). A decrease in the number of cortical granules has also been observed in aged mouse eggs (Xu et al., 1997).

In addition to these irregularities in cortical organization, spindle abnormalities have also been observed in aged eggs. TEM and light/fluorescence microscopy have shown that postovulatory aging affects the location of the metaphase II spindle in mouse and rabbit eggs (Longo, 1974b, Szollosi, 1971, Webb et al., 1986). In young mouse eggs, the spindle microtubules are oriented in parallel with the plasma membrane, but with increased post-ovulatory age, several abnormalities in the spindle have been observed in mouse and rabbit eggs. The spindle can rotate so that it is no longer parallel but has one spindle pole apparently still anchoring the spindle in the cortical region of the egg (Longo, 1974b, Szollosi, 1971). The spindle has also been observed to migrate toward the center of the egg, or to break down completely, resulting in the dispersing of chromosomes from the metaphase plate (Longo, 1974b, Szollosi, 1971, Webb et al., 1986).

\section{Membrane abnormalities in post-ovulatory aged eggs}

Reports of changes in membrane topography with post-ovulatory aging vary with species. Studies of mouse eggs have reported no significant morphological surface changes developing with post-ovulatory age (Longo, 1981, Szollosi, 1971), while aged eggs in other species (rabbit, hamster, human) have noteworthy abnormalities on the egg surface, including membrane blebbing, abnormally shaped bulbous microvilli, and release of fragments containing organelles such as cortical granules and endoplasmic reticulum (Longo, 1974a, Longo, 1974b, Sathananthan, 1994). It should be noted that spontaneous activation often accompanied post-ovulatory aging in hamster eggs (Longo, 1974a), and thus it is unknown if the changes that were observed due to agingassociated changes, activation-associated changes, or a combination.

Aged eggs also have abnormalities in egg membrane functionality. Normally, eggs undergo a transition from a membrane that is receptive to sperm in unfertilized eggs to a post-fertilization membrane that is unreceptive to sperm; this switch constitutes a membrane block to polyspermy. Our work suggests that aged eggs have abnormalities linked with both of these states: (1) aged eggs appear to be less able to support sperm-egg fusion, and are slower to fertilize than young eggs, in agreement with previous studies reporting reduced fertilization of aged mouse and human eggs in vitro (Park et al., 2000, Wolf and Hamada, 1976), and (2) aged eggs when inseminated ZP-free will become more polyspermic than will young eggs, suggestive a reduced ability to establish a membrane block to polyspermy (Wortzman and Evans, 2005). Both of these are of interest because of the correlation between post-ovulatory aging and reduced reproductive success (see above). In addition, data from several species indicate that the incidence of polyspermy increases with increased time after ovulation (Austin and Braden, 1953a, Austin and Braden, 1953b, Odor and Blandau, 1956, Yanagimachi and Chang, 1961), and an increased incidence of polyspermy raises the possibility that fertilized aged eggs have an impaired ability to prevent polyspermic fertilization.

Mammalian eggs use two types of blocks to polyspermy. The zona pellucida (ZP) block to polyspermy is the result of cortical granule (CG) exocytosis, triggered by the sperm-induced increase in cytosolic $\mathrm{Ca}^{2+}$ (Abbott and Ducibella, 2001, Yanagimachi, 1994). CG exocytosis does occur in fertilized aged eggs, and the extent of this is similar in aged and young eggs (Wortzman and Evans, 2005). This suggests that aged eggs can establish a ZP block to polyspermy, and raises the possibility that the increases in polyspermy in aged eggs may be due more to deficiencies in the membrane block than in the ZP block. The mechanistic basis of the membrane block is poorly understood, although evidence for mammalian eggs using a membrane block to prevent polyspermy comes from numerous studies in several species (Austin, 1961, Gardner and Evans, 2006, Horvath et al., 1993, Maluchnik and Borsuk, 1994, McAvey et al., 2002, Sengoku et al., 1995, Wolf, 1978, Zuccotti et al., 1991). Our recent data indicate that sperminduced $\mathrm{Ca}^{2+}$-dependent signaling plays a partial role in membrane block establishment (Gardner et al., 2007a, Gardner et al., 
2007b), but increased cytosolic $\mathrm{Ca}^{2+}$ alone is not sufficient and that some event(s) separable from sperm-induced $\mathrm{Ca}^{2+}$ signaling and linked with gamete membrane interactions is important for this switch in egg membrane function (Gardner et al., 2007b, Horvath et al., 1993, Wolf et al., 1979, Wortzman-Show et al., 2007). Our working model is that membrane block establishment occurs as a result of changes in the egg occurring with or downstream from the process of sperm-egg fusion, with one possibility being the changes induced in the egg membrane and cortex induced by the fertilizing sperm. The studies here examined unfertilized and fertilized aged eggs by scanning electron microscopy, to assess if there are differences in these sperm-induced changes occurring in aged eggs as compared to young eggs.

\section{Background on low-vacuum scanning electron micros- copy (LVSEM)}

We sought to test different modes of scanning electron microscopy (SEM) for our analyses of egg ultrastructure, for reasons that will be explained below. Therefore, it is worth reviewing the salient features of these technologies and how they compare. Previous studies of gamete ultrastructure have used conventional scanning electron microscopy, also referred to as high-vacuum SEM (HVSEM). HVSEM requires that the entire electron path, from gun to sample chamber, exist under high vacuum (e.g. $<10^{-6}$ Torr). This ensures minimal collisions of electrons with air molecules, good beam coherency, and optimal interaction of the electron beam with the sample surface in order to generate reflected electrons for good imaging. The detector used is the standard Eberhard-Thornly secondary electron detector. A second mode for SEM is lowvacuum-SEM (LVSEM). In LVSEM, the system operates at a significantly lower vacuum environment (higher pressure, e.g., $\sim 0.1$ to 1.0 Torr), utilizing low accelerating voltages $(1.0-5.0 \mathrm{kV})$, and enough air (typically water vapor) in the chamber to minimize 'pooling of electrons' (charging) and to amplify the electron signals for optimal imaging of the specimen. LVSEM typically utilizes a unique large field detector (LFD) that is sensitive to both secondary and back-scattered electrons. A third mode for SEM is environmental SEM (ESEM), which operates at a still higher pressure (considerably lower vacuum, 1.0-20 Torr). This mode differs in that gases (most commonly water vapor) can be present in the chamber at a very high pressure ( 26 mbar) thus requiring very high accelerating voltages (15-30 kV) and special gaseous detectors that utilize high water vapor for essential signal amplification. Charging is controlled by modulating chamber humidity, accelerating voltage, and spot size. Additionally, the working distance between sample and lens pole-piece is necessarily kept very small to minimize beam scattering and image degradation caused by electron beam interactions with water molecules. A Peltier-stage can be used to modulate temperature in conjunction with chamber pressure to achieve the optimal relative humidity in order to image fully hydrated, in some cases live, samples with minimal surface tension induced artifacts.

Both LVSEM and ESEM modes eliminate the need for metal coating of the sample by utilizing water vapor in conjunction with highly variable control of accelerating voltage and beam spot size to eliminate charging artifacts. In contrast, HVSEM sample preparations traditionally require sputter-coating the sample with a metal, typically gold or platinum. This electron conductive layer on specimens is necessary to dissipate the negative charge that would otherwise accumulate on the surface of the sample and distort the image. Thus, significant advantages of LVSEM are: (1) the ability to use low accelerating voltages (typically $<5.0 \mathrm{kV}$ and often as low as $1.0 \mathrm{kV}$ ) and, (2) the use of $\mathrm{H}_{2} \mathrm{O}$ vapor to mitigate charging and to amplify the secondary electron signal without the need for metal coating. In the low-vacuum environment, positive ions are generated during collisions between the electrons and $\mathrm{H}_{2} \mathrm{O}$ molecules that have been admitted to the chamber. These positive ions are attracted to the sample surface as the negative charge accumulates from the electron beam; in effect, charge on
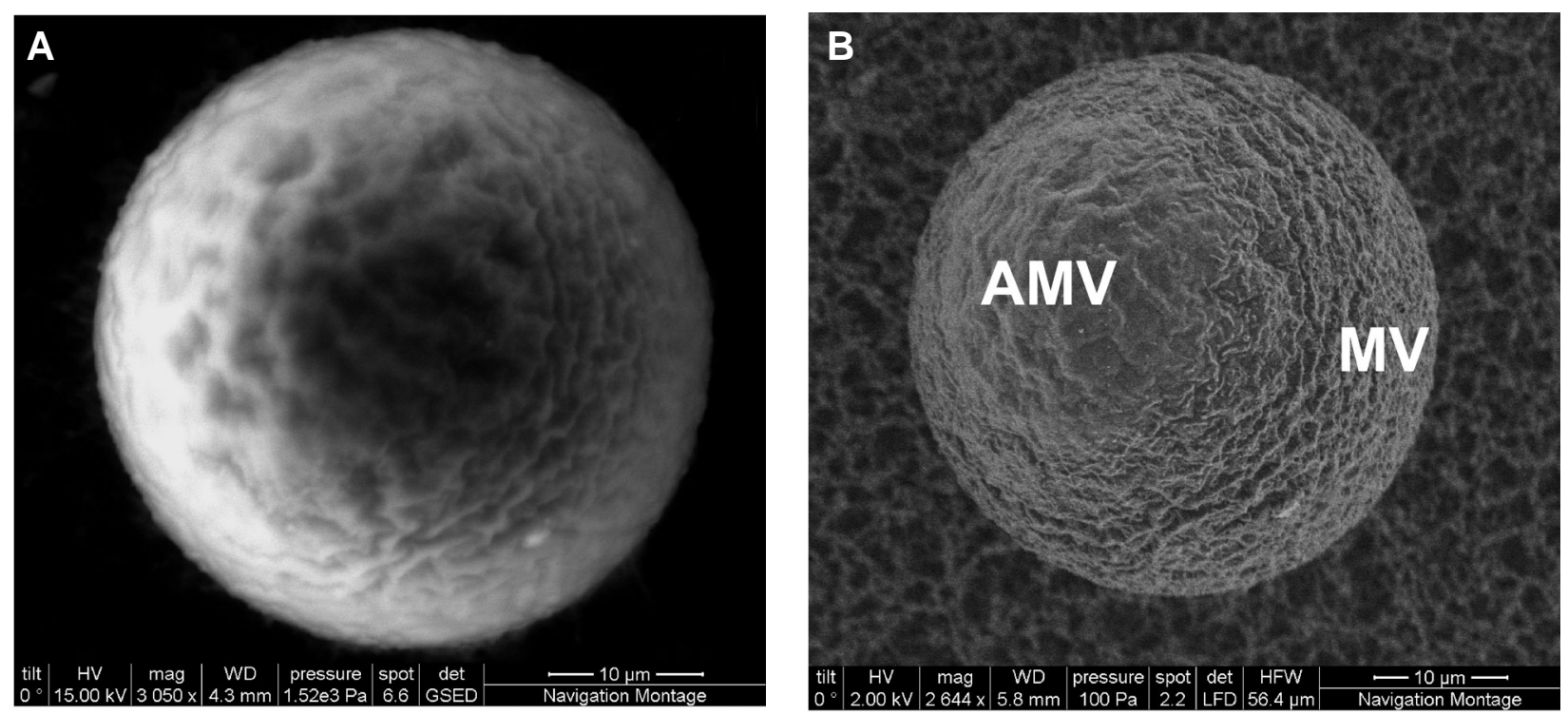

Fig. 1. The same zona pellucida-free unfertilized metaphase Il egg (collected at $\sim 13 \mathrm{~h}$ post-hCG) viewed using two different modes, ESEM and LVSEM, with the FEI Quanta 200 Environmental SEM. (A) The egg in ESEM mode in a humidified environment; (B) the same egg in LVSEM mode. Membrane surface details, namely the microvillar region (MV) and amicrovillar (AMV) region, were not appreciably visible in ESEM with the conditions used here. Imaging of eggs for the remainder of this work utilized LVSEM mode. Scale bars, $10 \mu \mathrm{m}$. 

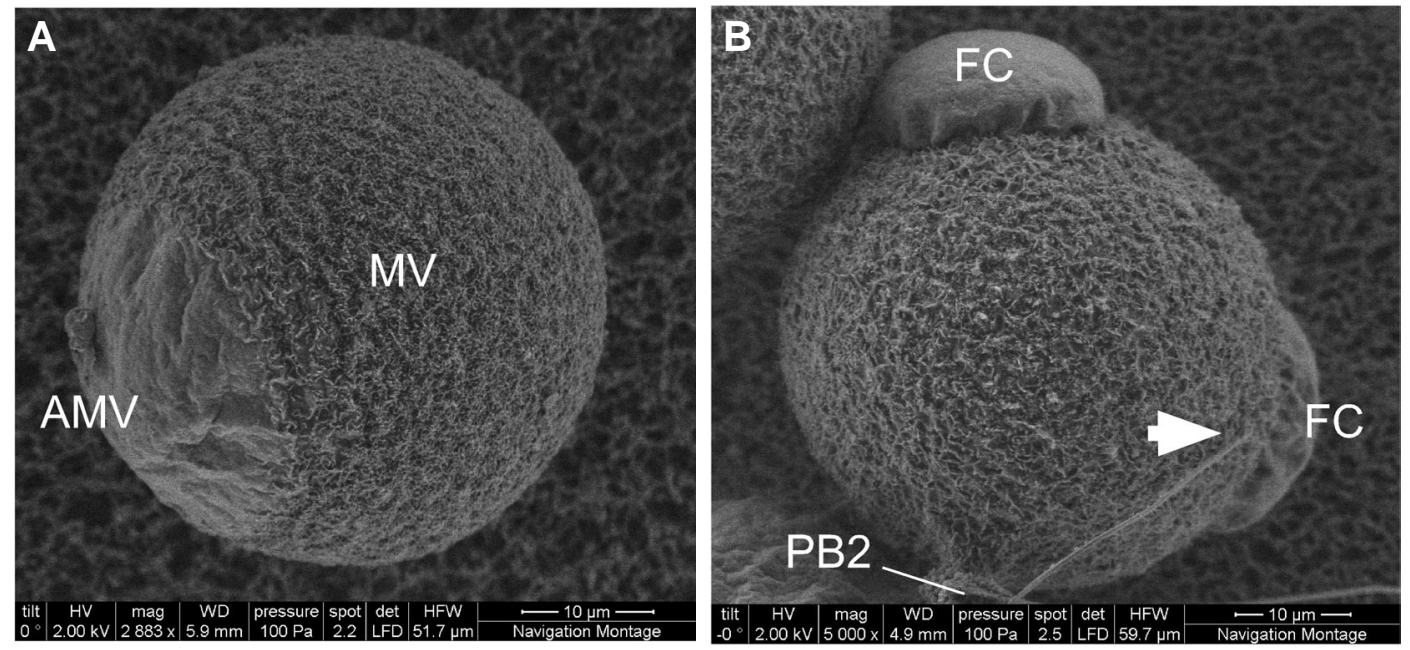

Fig. 2. These panels show control young (collected at $13 \mathrm{~h}$ posthCG) ZP-free eggs. (A) An unfertilized egg, with MV identifying the microvillar region of the egg surface, and AMV identifying the amicrovillar region, which overlies an actin-rich-cap over the meiotic spindle. (B) A fertilized egg fixed at $2.5 \mathrm{~h}$ post-insemination; this egg was fertilized by two sperm. FC identifies the two fertilization cones, the microvilli-free regions that overlie the decondensing sperm DNA in the egg cortex. The sperm tail for one of these fertilizing sperm is visible (arrowhead). The second polar body (PB2) is just outside of the field of view. Scale bars, $10 \mu \mathrm{m}$.

the surface of the sample in LVSEM mode is effectively neutralized, thus preventing charge accumulation (Muscariello et al., 2005, Sammons and Marquis, 1997, Stokes, 2003, Thiel and Toth, 2005). In the LVSEM mode, samples are imaged with the LFD in conjunction with a low-kilovolt $(\mathrm{kV})$ cone to minimize electron- $\mathrm{H}_{2} \mathrm{O}$ interactions in order to maintain beam coherency and optimally utilizes a working distance of $\sim 5 \mathrm{~mm}$. LVSEM proved to be excellent for high contrast imaging of the egg surface/plasma membrane because of the large field detector's sensitivity to both primary and secondary electrons.

The standard protocol for HVSEM sample preparations also involves a process known as critical-point drying (CPD), whereby samples are dried at a specific temperature and pressure. Preparation of samples for SEM often substitutes hexamethyldisilazane (HMDS) for conventional CPD. HMDS is a solvent with an extremely low vapor pressure that eliminates surface tension induced artifacts caused during sample drying. The use of HMDS is also a safer and cost-effective alternative to CPD. Several previous studies have shown that the use of HMDS yields comparable results as those obtained with identical biological specimens or sample tissues prepared with CPD (Bray et al., 1993, Hochberg and Litvaitis, 2000, Kennedy et al., 1989, Nation, 1983, Slizova et al., 2003, Ubero-Pascal et al., 2005). The data presented here demonstrate that application of HMDS to LVSEM sample preparation is appropriate for preserving and drying mammalian eggs and early zygotes. Thus, the aforementioned modifications to conventional protocols for SEM sample preparations provide an improved approach to record detailed surface and topographical images of gamete interactions.

\section{Results}

Comparison of two different environments of scanning electron microscopy to view zona pellucida-free mouse eggs

The FEI Quanta 200 Environmental SEM ${ }^{T M}$ we used in this study has three operating modes: HVSEM, LVSEM, and ESEM modes. To investigate approaches for imaging mouse egg surface topography, we first performed studies comparing ESEM and LVSEM; an example of the results of this work is shown in Fig. 1. Egg samples were first viewed under the environmental-SEM mode with the use of a gaseous secondary electron detector (GSED). Eggs were viewed in a high relative humidity environment, where a condensed water vapor layer accumulates on the surface of the egg, as depicted in Fig. $1 \mathrm{~A}$. ESEM mode, while providing information about sample responses to different environmental conditions (i.e., different relative humidity levels, temperatures, and pressures), appeared not to be optimal for imaging of fine surface details such as microvilli on the egg membrane, as the layer of water vapor on the sample resulted in low contrast and limited visualization of fine structural details (Muscariello et al., 2005). The same egg, viewed in ESEM mode as shown in Fig. $1 \mathrm{~A}$, was then examined under a low, or reduced, vacuum environment (LVSEM mode) (Fig. 1B). LVSEM imaging with a large field detector and a lo-kV cone was found to be the most appropriate/ effective mode of scanning electron microscopy for studies of membrane topography, and this operating mode was used throughout the remainder of these studies to characterize egg membrane topography.

\section{LVSEM analysis of the effects of post-ovulatory aging on egg membrane topography}

It has been reported that post-ovulatory aged eggs at 22 hours post-hCG have reduced fertilizability and reduced ability to establish the membrane block if they are fertilized (Wortzman and Evans, 2005). Here we tested the hypothesis that abnormalities in the membrane surface could contribute to the observed defects in egg membrane functions in post-ovulatory aged eggs. LVSEM was used to characterize membrane topography in post-ovulatory aged eggs before and after fertilization.

Figure 2 shows control unfertilized and fertilized «young» eggs, collected at $\sim 13 \mathrm{hr}$ post-hCG. Unfertilized young eggs prepared in the absence of a metal coating and conventional CPD and examined under LVSEM mode (Fig. 2A) display the characteristic surface polarity previously described in other ultrastructural studies: the amicrovillar (AMV) and microvillar (MV) regions. The AMV region overlies the metaphase II spindle and the associated actin-rich cap, and is the site from which the egg undergoes its asymmetric cytokinesis and extrudes the second polar body. The remainder of the egg membrane surface is covered in microvilli, known to be the region 

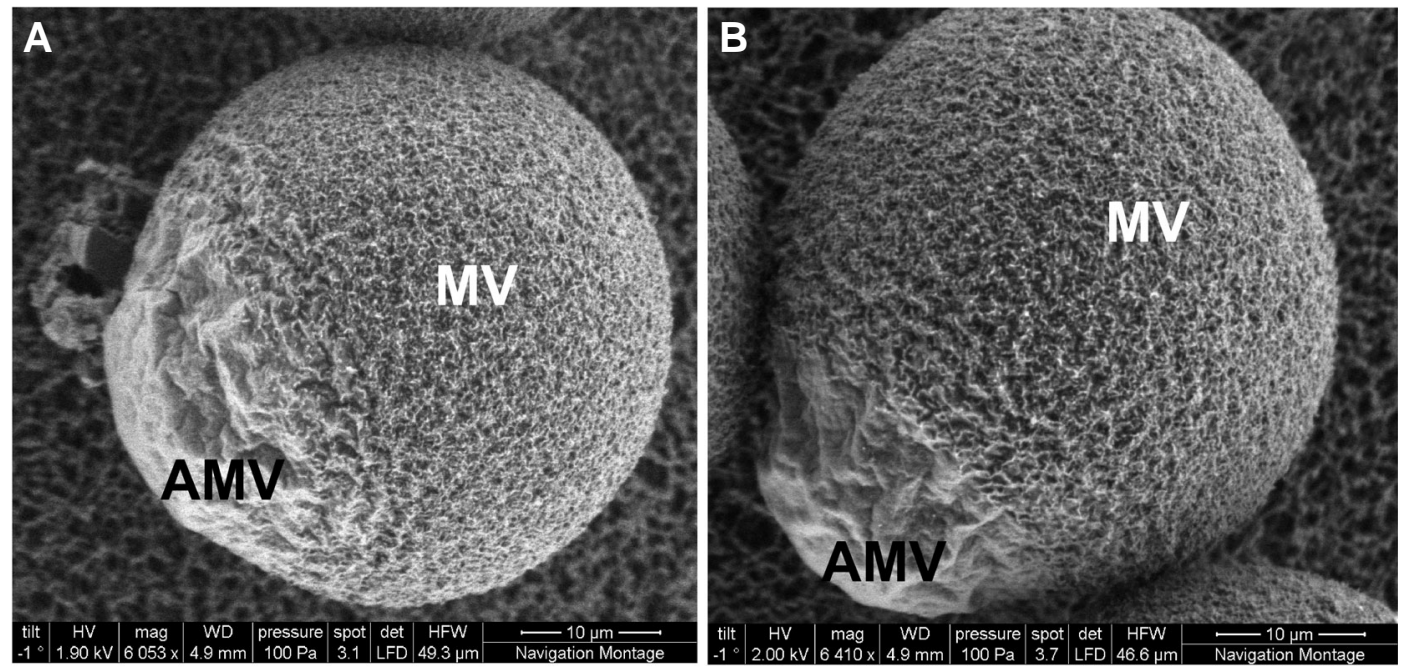

Fig. 3. Aged (collected at $22 \mathrm{~h}$ post-hCG) zona pellucida-free unfertilized eggs. MV identifyies the microvillar region of the egg surface, and AMV identifies the amicrovillar region, which overlies and actin-rich cap over the meiotic spindle. Note that the amicrovillar region is significantly more distended than in the young unfertilized egg (Fig. 2A), in agreement with our studies using phalloidin staining to examine F-actin localization in aged eggs (Wortzman and Evans, 2005). Scale bars, $10 \mu \mathrm{m}$.

where sperm binding and fusion preferentially occur during fertilization. Fertilized young eggs fixed at $2.5 \mathrm{hr}$ post-insemination show the formation of microvilli-free fertilization cones over sperm incorporation sites (Fig. 2B).

Unfertilized aged eggs had a morphological abnormality in the AMV regions overlying the maternal DNA, with the AMV region having a dramatic protrusion (Fig. 3), as opposed to the flatter and smoother AMV surfaces in young unfertilized eggs (Fig. 2A). A total of 27 unfertilized aged eggs were examined, and the AMV region could be viewed in 14 of these; the AMV regions showed this extended appearance of in 13 of these 14 eggs, whereas only one egg had an apparently normal AMV region similar to the flatter, smoother AMV surfaces in young unfertilized eggs. This observation of alarge protrusion over the AMV region complements our laboratory's previous studies of cytoskeletal changes in post-ovulatory aged unfertilized eggs, noting a dramatic actin-rich protrusion over the site of the maternal DNA in some eggs (Wortzman and Evans, 2005). The morphology of the microvillar surface in aged eggs did not differ significantly from the microvillar surface in young unfertilized eggs (Fig. 2), in agreement with a previous HVSEM study of post-ovulatory aged mouse eggs (Longo, 1981).

In fertilized post-ovulatory aged eggs, three different phenotypes were observed in the 31 fertilized post-ovulatory aged eggs that were examined (Figs. 4-6). The first phenotype in aged fertilized eggs was a normal microvillar surface, (i.e., similar to the microvilli visible on young fertilized eggs, Fig. 2A), but with fertilization cones that were increased in elevation and with a wrinkled appearance (Fig. 4; 13 of the 31 total fertilized aged eggs examined). These differed from the less protruded and smoother fertilization cones in young fertilized eggs fixed at 2.5 hours post-insemination (Fig. 2B). The second phenotype observed in these aged eggs, examples of which are in Fig. 5, was a microvillar region with the occasional presence of bulblike vesicles (observed in nine of 31 eggs examined), as well as small, distinct pits (observed in six of 31 eggs examined); these structures were not observed in young fertilized eggs (Fig. 2A). Finally, the third phenotype in fertilized aged eggs was small amicrovillar patches over the site of sperm incorporation (Fig. 6; observed in 11 of the 31 eggs examined). These small amicrovillar patches in fertilized aged eggs fixed at 2.5 hours post-insemination were in stark contrast to the elevated, amicrovillar fertilization cones in young fertilized eggs fixed
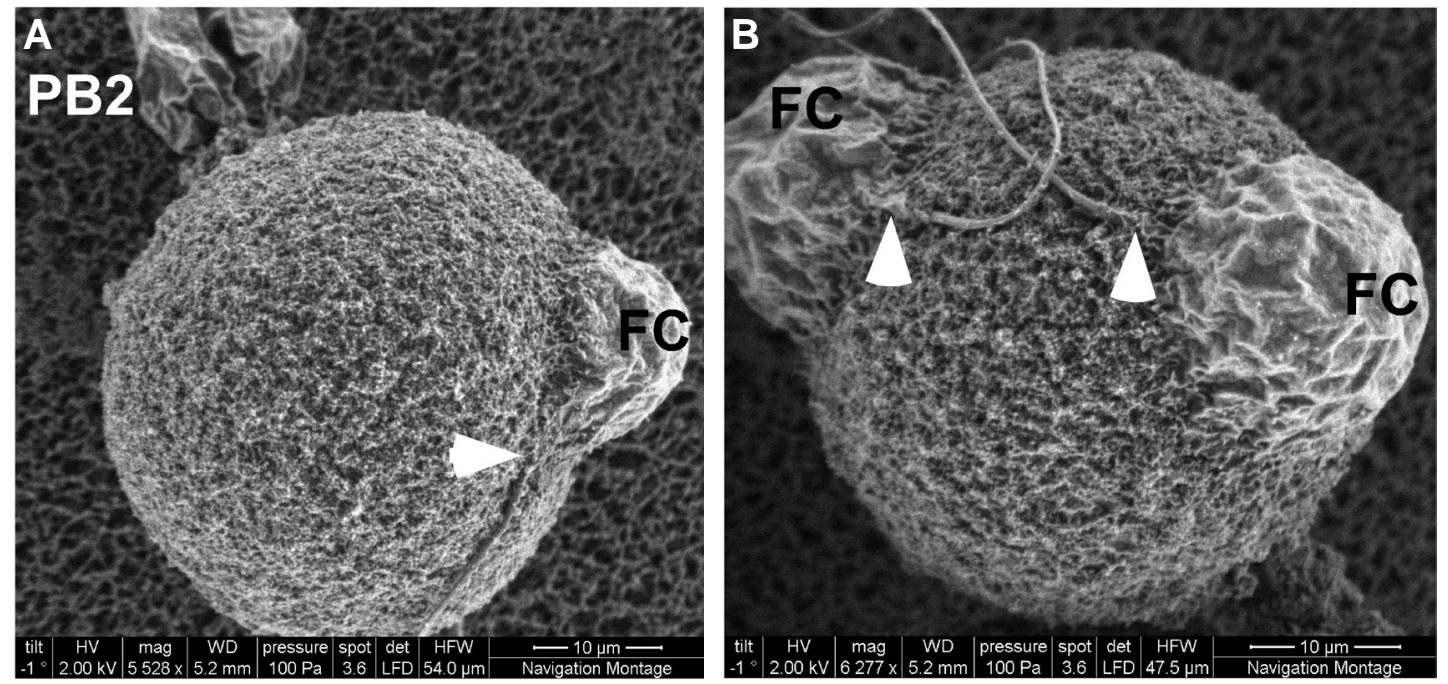

Fig. 4. Aged (collected at $22 \mathrm{~h}$ post-hCG) zona pellucidafree fertilized eggs fixed at $2.5 \mathrm{~h}$ post-insemination. Examples of one of the three different characteristic appearances observed in these studies are shown in this figure. The eggs in $(\mathbf{A}, \mathbf{B})$ have what appear to be largely normal microvillar surfaces, but have fertilization cones (FC) that appear to be more elevated and more wrinkled that those observed in young fertilized eggs (Fig. 2B). The second polar body (PB2) is visible in the egg in (A). The egg in (B) was fertilized by two sperm and thus had two fertilization cones. Arrowheads mark where the sperm tail can be seen emerging from the sperm entry site. Scale bars, $10 \mu \mathrm{m}$. 

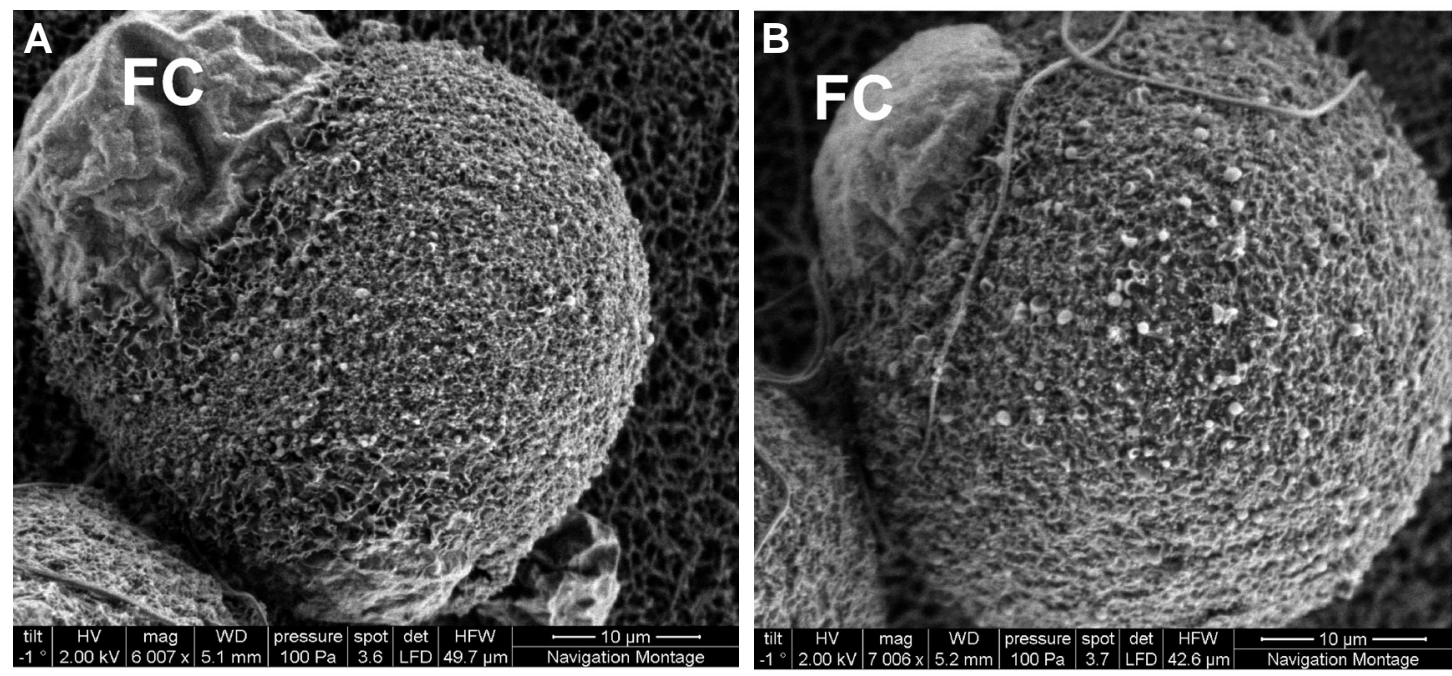

Fig. 5. Aged (collected at $22 \mathrm{~h}$ post-hCG) zona pellucidafree fertilized eggs fixed at $2.5 \mathrm{~h}$ post-insemination. Examples of one of the three different characteristic appearances observed in these studies are shown in this figure. Similar to the eggs in Fig. 4, these eggs have fertilization cones over the decondensing sperm DNA in the egg cortex; the fertilization cone in the egg in (A) is oversized, similar to those in Fig. 4B. Unlike the eggs in Fig. 4, the eggs here have abnormal surfaces characterized by a mixture of pits and bulb-like vesicles. Scale bars, $10 \mu m$.

at 2.5 hours post-insemination (Fig. 2B), and to the wrinkled, hyperelevated fertilization cones observed in a subset of fertilized aged eggs (Fig. 4, 5A). These small amicrovillar patches appear to be similar to the amicrovillar patches over sperm incorporation sites in fertilized young eggs fixed at much earlier post-insemination times (data not shown), and this is consistent with observations that postovulatory aged eggs can show delayed fertilization (Wortzman and Evans, 2005).

\section{Discussion}

The aging of the egg in the oviduct following ovulation is linked with reduced reproductive success. This study examined the effects of post-ovulatory aging on the egg plasma membrane using scanning electron microscopy. In the course of these studies, we tested both ESEM and LVSEM modes of the FEI Quanta 200 Environmental SEM ${ }^{\mathrm{TM}}$. While ESEM mode was not sufficient under the conditions we used to observe fine cell surface details (e.g., microvilli), the LVSEM mode proved to be an excellent way to view the egg surface. To our knowledge, this is the first use of ESEM and LVSEM to examine mammalian eggs. It should be noted that the use of LVSEM presents advantages over HVSEM conventionally used, in ease and cost-effectiveness of sample preparation and in minimizing risk of artifacts that could possibly result from certain steps of HVSEM sample preparation (sputter-coating the sample with a metal, or critical point drying).

Our previous work has shown that post-ovulatory aged eggs have two abnormalities in egg membrane function. First, ZP-free
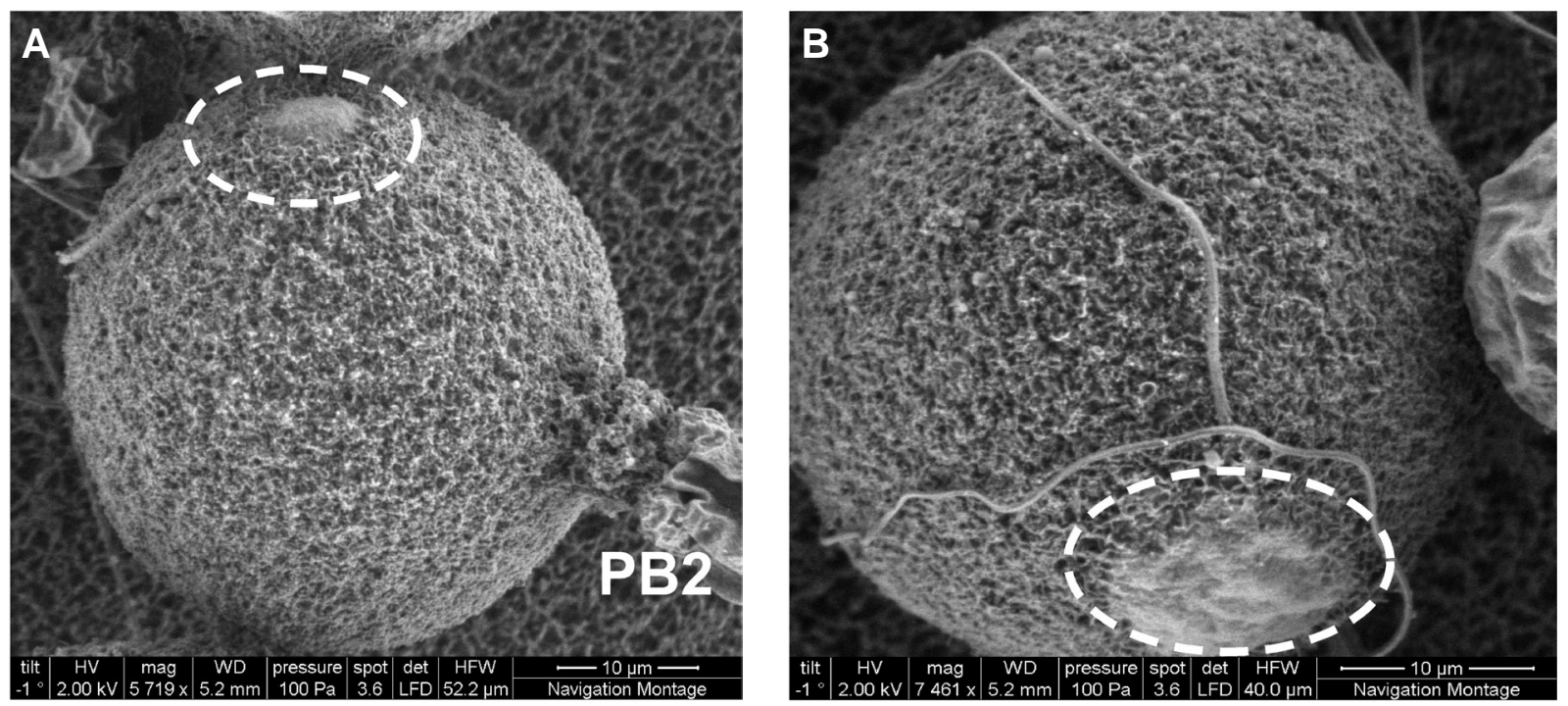

Fig. 6. Aged (collected at $\mathbf{2 2} \mathbf{h}$ post-hCG) zona pellucida-free fertilized eggs fixed at $\mathbf{2 . 5} \mathbf{h}$ post-insemination. Examples of one of the three different characteristic appearances observed in these studies are shown in this figure. The eggs here in (A,B) have small amicrovillar patches over the decondensing sperm DNA in the egg cortex (marked by dotted line circles), thus appearing to be in the early stages of fertilization prior to the development of fertilization cones. This may be due to the fact that post-ovulatory aged eggs appear to be slower to fertilize than young eggs (Wortzman and Evans, 2005). The second polar body (PB2) is visible in the egg in (B). Scale bars, $10 \mu \mathrm{m}$. 
aged eggs were slower to fertilize, showing a delay of $\sim 2.5 \mathrm{hr}$ to achieve similar levels of fertilization and sperm-egg fusion when compared to young eggs under identical insemination conditions. This appears to be a deficiency in sperm-egg fusion, as spermegg binding was similar in young and aged eggs (Wortzman and Evans, 2005). Second, if aged eggs were fertilized and induced to undergo the egg-to-embryo transition, they appeared to have a reduced ability to establish a membrane block to polyspermy, as evidenced by increased sperm-egg fusion observed when ZPfree aged eggs were inseminated (Wortzman and Evans, 2005). We undertook this investigation to examine if aged eggs have abnormalities in membrane organization that might be detected with the use of ESEM or LVSEM (as an improvement over previous work using HVSEM), and that such abnormalities in aged eggs could be contributing to the delay in fertilization or to the reduced establishment of the membrane block.

Our analyses of unfertilized eggs do not reveal any gross differences in the microvillar regions (the region to which sperm bind and fuse) but the amicrovillar domains of aged eggs do differ from those of young eggs, with this region appearing significantly more distended and wrinkled. It is possible that the changes that occur in the amicrovillar region also somehow transmit modifications throughout the egg surface. Moreover, while no overt differences were observed in the microvillar region by LVSEM, it is clearly possible that more subtle differences may exist in the membrane and/or in the underlying cortical region in the cytoplasm. Such differences could contribute to abnormalities in receptivity to sperm and/or to the egg's ability to regulate receptivity to sperm (e.g., establishing a membrane block to polyspermy post-fertilization).

Examinations of fertilized aged eggs revealed noteworthy differences as compared to fertilized young eggs. There was variability in the aged eggs, with three different phenotypes observed here. The small amicrovillar patches over sperm incorporation sites, observed in some eggs and shown in Fig. 6, appear to be consistent with our results detecting a delay in fertilization of aged eggs (Wortzman and Evans, 2005). At the other end of the spectrum, some aged eggs were found to have elevated and wrinkled fertilization cones, differing noticeably from fertilization cones in young eggs. The significance of these differences in the fertilization cone is unclear, but it is possible that these abnormalities in sperm-induced surface remodeling are somehow linked with the aberrant membrane block in aged eggs. We also observed what appear to be vesicles and pits on the surfaces of some fertilized aged eggs, which were not observed in fertilized young eggs. Aged eggs undergo premature cortical granule exocytosis as a result of the aging process, without fertilization (Xu et al., 1997); it is possible that the vesicles and pits observed here are somehow related to this precocious exocytosis and cortical granules loss. The pits in aged fertilized mouse eggs seem similar to the "membrane-delimited craters...termed cortical crypts" observed in zebrafish eggs, structures which are described as remnants of exocytosed cortical granules (Becker and Hart, 1999). The vesicles observed here on aged eggs appear to be membrane blebs, in agreement with reports of membrane blebbing, abnormally shaped microvilli, and release of cytoplasmic fragments observed in aged rabbit, hamster and human eggs (Longo, 1974a, Longo, 1974b, Sathananthan, 1994), and similar to membrane blebs observed in mouse eggs treated with the microfilament disruptor cytochalasin B (Longo and Chen, 1985). Interestingly, cytoplasmic and DNA fragmentation has been observed in aged eggs activated with an extract of soluble sperm (Gordo et al., 2002, Gordo et al., 2000), suggesting that sperm-induced $\mathrm{Ca}^{2+}$ signaling can trigger apoptosis-like responses in aged eggs; the membrane abnormalities observed here in fertilized aged eggs may be linked with the way an aged eggs responds to increased cytosolic $\mathrm{Ca}^{2+}$, clearly differing from the responses in a young, healthy egg.

Based on these data and the data from past work on postovulatory aging (see Introduction), clearly there are multiple and varied effects of cellular aging on the female gamete; this was particularly evident here based on the range of different effects observed in fertilized aged eggs. The deficiencies in fertilized aged eggs could be due to the abnormalities in $\mathrm{Ca}^{2+}$ signaling and poor execution of the egg-to-embryo transition, and/or due to abnormalities that are present in unfertilized aged eggs that then predestine the egg to other defects after fertilization. The abnormalities in egg membrane function and topography are potential contributors, along with other changes developing with increased time after ovulation, to the association of post-ovulatory aging with poor reproductive outcomes.

\section{Materials and Methods}

\section{Egg collection and zona pellucida removal}

Throughout this work, the term "egg" is used for the ovulated female gamete in the oviduct and arrested in metaphase II. Egg collection and ZP removal was performed as previously described (McAvey et al., 2002, Wortzman and Evans, 2005). Eggs were collected from the oviducts of from 6-8 week-old superovulated CF1 mice (Harlan, Indianapolis, IN) at 13 or $22 \mathrm{hr}$ after injection with human chorionic gonadotropin (hCG) to induce ovulation. Eggs collected at $13 \mathrm{hr}$ post-hCG are referred to here as "young eggs, " and eggs collected at $22 \mathrm{hr}$ post-hCG are referred to as "aged eggs.» These post-hCG times for egg collection were based on previous studies on post-ovulatory aging in mouse eggs (Abbott et al., 1998, Xu et al., 1997). Mice ovulate at $\sim 12$ hours post hCG-injection; the aged eggs used here collected at $22 \mathrm{hr}$ post-hCG have been aging in the oviduct for $\sim 10$ hours prior to collection. It should be noted that some aged eggs undergo spontaneous egg activation (Wortzman and Evans, 2005, Xu et al., 1997); aged eggs that had emitted a second polar body were not used for IVF studies.

Cumulus cells were removed from eggs by brief incubation $(<5 \mathrm{~min})$ in Whitten's medium (109.5 mM NaCl, $4.7 \mathrm{mM} \mathrm{KCl}, 1.2 \mathrm{mM} \mathrm{KH}_{2} \mathrm{PO}_{4}, 1.2 \mathrm{mM}$ $\mathrm{MgSO}_{4}, 5.5 \mathrm{mM}$ glucose, $0.23 \mathrm{mM}$ pyruvic acid, $4.8 \mathrm{mM}$ lactic acid hemicalcium salt; $\mathrm{Ca}^{2+}$ concentration is $2.4 \mathrm{mM}$ (Whitten, 1971) with $7 \mathrm{mM}$ $\mathrm{NaHCO}_{3}$ and 15 mM HEPES (hereafter referred to as "Whitten's-HEPES"), containing $30 \mathrm{mg} / \mathrm{ml} \mathrm{BSA}$ (Albumax I from Gibco-BRL, Gaithersburg, MD) and $0.025 \%$ Type IV-S hyaluronidase (Sigma; St. Louis, MO). Following removal of the cumulus cells, ZP removal was performed by brief incubation ( $10 \mathrm{sec})$ in acidic culture medium compatible buffer $(10 \mathrm{mM}$ HEPES, $1 \mathrm{mM} \mathrm{NaH}_{2} \mathrm{PO}_{4}, 0.8 \mathrm{mM} \mathrm{MgSO}_{4}, 5.4 \mathrm{mM} \mathrm{KCl}, 116.4 \mathrm{mM} \mathrm{NaCl}$, $\mathrm{pH}$ 1.5). Eggs then recovered for 60 minutes in Whitten's medium containing $22 \mathrm{mM} \mathrm{NaHCO}_{3}$ (hereafter referred to as "Whitten's-Bicarb") and $15 \mathrm{mg} / \mathrm{ml} \mathrm{BSA}$. Eggs were cultured at $37^{\circ} \mathrm{C}$ in a humidified atmosphere of $5 \% \mathrm{CO}_{2}$ in air.

\section{Sample preparation for low-vacuum scanning electron microscopy (LVSEM)}

Nine-well Pyrex spot plates (Corning, NY) were used to treat eggs during the fixation, buffer washes, and osmication steps. Eggs were fixed in $3 \%$ formaldehyde $+1.5 \%$ glutaraldehyde in $100 \mathrm{mM}$ sodium cacodylate buffer $+5 \mathrm{mM}$ calcium $+2.5 \%$ sucrose, $\mathrm{pH} 7.4$ at room temperature for 
1.25-1.5 hours. Eggs were then washed three times for 15 min each in 100 $\mathrm{mM}$ sodium cacodylate $+2.5 \%$ sucrose buffer, $\mathrm{pH} 7.4$ (Electron Microscopy Sciences; Hatfield, PA). Following these washes, the eggs were post-fixed in a fume hood on ice for $1 \mathrm{hr}$ in freshly-prepared Palade's osmium tetroxide $(1.0 \mathrm{ml}$ Acetate-Veronal Stock [ $1.15 \mathrm{~g}$ sodium acetate anhydrous, $2.943 \mathrm{~g}$ sodium barbituate, brought to $100 \mathrm{ml}$ with $\mathrm{ddH}_{2} \mathrm{O}$,], $1.25 \mathrm{ml} 4 \% \mathrm{OsO}_{4}, 1.0 \mathrm{ml} 0.1 \mathrm{~N} \mathrm{HCl}, 1.75 \mathrm{ml} \mathrm{ddH}_{2} \mathrm{O}$ ). Eggs were then transferred to a 96-well plate for the remainder of the egg preparation steps. Eggs were briefly rinsed in $\mathrm{ddH}_{2} \mathrm{O}$ and $4^{\circ} \mathrm{C} 50 \%$ ethanol, and then dehydrated in a graded, $4^{\circ} \mathrm{C}$ ethanol series, 15 min each: $70 \%, 95 \%$, and $100 \%$. Another wash in fresh $100 \%$ ethanol at room temperature for 15 min followed the dehydration series. Two washes for $15 \mathrm{~min}$ each in a $50: 50$ solution of $100 \%$ ethanol and hexamethyldisilazane (HMDS; Electron Microscopy Sciences) were then performed. Finally, two washes for 15 min each in $100 \%$ HMDS were conducted. Eggs were then transferred from HMDS to small pieces of $25 \mathrm{~mm}$ cellulose-nitrate filter circles (Whatman), and allowed to air-dry overnight taped to small Petri dishes.

The eggs, adhered to cellulose-nitrate filters, were mounted onto double-sided carbon tape on a small, circular metal stub, and samples were observed with an FEI Quanta 200 Environmental Scanning Electron Microscope. Under LVSEM mode, egg samples were viewed with a large field detector and a low-kilovolt (lo-kV) cone, allowing for a field of view that was unrestricted and reducing secondary electron beam loss to the air. Images were optimized by modulating, within a small range, the following parameters (which are noted below each image): an accelerating voltage (HV) of $1.90-2.0 \mathrm{kV}$, a working distance (WD) of $5.0-5.5 \mathrm{~mm}$, a chamber pressure of $0.75 \operatorname{Torr}(100 \mathrm{~Pa})$, and a spot size of 3.0-3.8. A Navigation Montage (scanning working distance of $5.9 \mathrm{~mm}$ ) was used to map the location of egg samples on the filter paper within the electron chamber. For ESEM mode, egg samples were viewed with a gaseous secondary electron detector (GSED) in a humidified environment. The system was operated under high accelerating voltages $(15.0 \mathrm{kV})$ and high chamber pressure (690-1520 Pa, or 5.0-11.5 Torr).

\section{Acknowledgements \\ This was part of the Master's of Science research project of D.T.D., done in collaboration with J.M.M. This work supported by research grants to J.P.E. (March of Dimes, 6-FY04-59; N.I.H., R01 HD037696 and R01 HD045671).}

\section{References}

ABBOTT, A.L. and DUCIBELLA, T. (2001). Calcium and the control of mammalian cortical granule exocytosis. Front.Biosci. 6: D792-D806.

ABBOTT, A.L., XU, Z., KOPF, G.S., DUCIBELLA, T. and SCHULTZ, R.M. (1998). In vitro culture retards spontaneous activation of cell cycle progression and cortical granule exocytosis that normally occur in in vivo unfertilized mouse eggs. Biol.Reprod. 59: 1515-1521.

AUSTIN, C.R. (1961). The mammalian egg. Charles C. Thomas, Springfield, IL.

AUSTIN, C.R. and BRADEN, A.W.H. (1953a). An investigation of polyspermy in the rat and rabbit. Aust.J.Biol.Sci. 6: 674-693.

AUSTIN, C.R. and BRADEN, A.W.H. (1953b). Polyspermy in mammals. Nature 172: 82-83.

AUSTIN, C.R. and BRADEN, A.W.H. (1956). Early reaction of the rodent egg to spermatozoa penetration. J.Exp.Zool. 33: 358-365.

BECKER, K.A. and HART, N.H. (1999). Reorganization of filamentous actin and myosin-II in zebrafish eggs correlates temporally and spatially with cortical granule exocytosis. J Cell Sci112 (Pt 1): 97-110.

BLANDAU, R.J. and JORDAN, E.S. (1941). The effect of delayed fertilization on the development of the rat ovum. Amer J Anat 68: 275-291.

BLANDAU, R.J. and YOUNG, W.C. (1939). The effects of delayed fertilization on the development of the guinea pig ovum. Amer J Anat 64: 303-329.

BRAY, D.F., BAGU, J. and KOEGLER, P. (1993). Comparison of hexamethyldisilazane (HMDS), Peldri II, and critical-point drying methods for scanning electron microscopy of biological specimens. Microsc Res Tech 26: 489-95.

DUCIBELLA, T. (1998). Biochemical and cellular insights into the temporal window of normal fertilization. Theriogenology. 49: 53-65.

DUCIBELLA, T., SCHULTZ, R.M. and OZIL, J.P. (2006). Role of calcium signals in early development. Semin Cell Dev Biol 17: 324-32.

FISSORE, R.A., KUROKAWA, M., KNOTT, J., ZHANG, M. and SMYTH, J. (2002). Mechanisms underlying oocyte activation and postovulatory aging. Reproduction 124: 745-754.

GARDNER, A.J. and EVANS, J.P. (2006). Mammalian membrane block to polyspermy: new insights into how mammalian eggs prevent fertilisation by multiple sperm. Reprod Fertil Dev 18: 53-61.

GARDNER, A.J., KNOTT, J.G., JONES, K.T. and EVANS, J.P. (2007a). CaMKII can participate in but is not sufficient for the establishment of the membrane block to polyspermy in mouse eggs. J. Cell. Physiol. 212: 275-280.

GARDNER, A.J., WILLIAMS, C.J. and EVANS, J.P. (2007b). Establishment of the mammalian membrane block to polyspermy: Evidence for calcium-dependent and -independent regulation. Reproduction 133: 383-393.

GORDO, A.C., RODRIGUES, P., KUROKAWA, M., JELLERETTE, T., EXLEY, G.E., WARNER, C. and FISSORE, R. (2002). Intracellular calcium oscillations signal apoptosis rather than activation in in vitro aged mouse eggs. Biol. Reprod. 66: 1828-37.

GORDO, A.C., WU, H., HE, C.L. and FISSORE, R.A. (2000). Injection of sperm cytosolic factor into mouse metaphase II oocytes induces different developmental fates according to the frequency of $\mathrm{Ca}^{2+}$ oscillations and oocyte age. Biol. Reprod. 62: 1370-1379.

GRAY, R.H., SIMPSON, J.L., KAMBIC, R.T., QUEENAN, J.T., MENA, P., PEREZ, A. and BARBATO, M. (1995). Timing of conception and the risk of spontaneous abortion among pregnancies occurring during the use of natural family planning. Am J Obstet Gynecol172: 1567-72.

GUERRERO, R. and LANCTOT, C.A. (1970). Aging of fertilizing gametes and spontaneous abortion: Effect of the day of ovulation and the time of insemination. Amer J Obstet Gynec 107: 263-267.

GUERRERO, R. and ROJAS, O.I. (1975). Spontaneous abortion and aging of human ova and spermatozoa. N Eng/J Med 293: 573-5.

HARDMAN, J.G. and GILMAN, A.G. (2007). David L. Garbers (1944-2006). Annual Review of Physiology 69.

HOCHBERG, R. and LITVAITIS, M.K. (2000). Hexamethyldisilazane for scanning electron microscopy of Gastrotricha. Biotech Histochem 75: 41-4.

HORVATH, P.M., KELLOM, T., CAULFIELD, J. and BOLDT, J. (1993). Mechanistic studies of the plasma membrane block to polyspermy in mouse eggs. Mol. Reprod. Dev. 34: 65-72.

IGARASHI, H., TAKAHASHI, E., HIROI, M. and DOI, K. (1997). Aging-related changes in calcium oscillations in fertilized mouse oocytes. Mol.Reprod.Dev. 48: 383-390.

JONES, K.T. and WHITTINGHAM, D.G. (1996). A comparison of sperm- and $\mathrm{IP}_{3^{-}}$ induced $\mathrm{Ca} 2+$ release in activated and aging mouse oocytes. Dev. Biol. 178: 229-237.

KENNEDY, J.R., WILLIAMS, R.W. and GRAY, J.P. (1989). Use of Peldri II (a fluorocarbon solid at room temperature) as an alternative to critical point drying for biological tissues. J Electron Microsc Tech 11: 117-25.

LONGO, F.J. (1974a). An ultrastructural analysis of spontaneous activation of hamster eggs aged in vivo. Anat Rec 179: 27-55.

LONGO, F.J. (1974b). Ultrastructural changes in rabbit eggs aged in vivo. Biol Reprod 11: 22-39.

LONGO, F.J. (1981). Changes in the zones pellucidae and plasmalemma of aging mouse eggs. Biol Reprod 25: 399-411.

LONGO, F.J. (1985). Fine structure of the mammalian egg cortex. Am J Anat 174: 303-315.

LONGO, F.J. and CHEN, D.Y. (1985). Development of cortical polarity in mouse eggs: Involvement of the meiotic apparatus. Dev.Biol. 107: 382-394.

LOPATA, A., SATHANANTHAN, A.H., MCBAIN, J.C., JOHNSTON, W.I. and SPEIRS, A.L. (1980). The ultrastructure of the preovulatory human egg fertilized in vitro. Fertil Steril33: 12-20.

MALCUIT, C., KUROKAWA, M. and FISSORE, R.A. (2006). Calcium oscillations 
and mammalian egg activation. J Cell Physio/206: 565-73.

MALUCHNIK, D. and BORSUK, E. (1994). Sperm entry into fertilised mouse eggs. Zygote 2: 129-131.

MCAVEY, B.A., WORTZMAN, G.B., WILLIAMS, C.J. and EVANS, J.P. (2002). Involvement of calcium signaling and the actin cytoskeleton in the membrane block to polyspermy in mouse eggs. Biol. Reprod. 67: 1342-1352.

MURRAY, A. and HUNT, T. (1993). The Cell Cycle: An Introduction. W.H. Freeman and Company, New York.

MUSCARIELLO, L., ROSSO, F., MARINO, G., GIORDANO, A., BARBARISI, M., CAFIERO, G. and BARBARISI, A. (2005). A critical overview of ESEM applications in the biological field. J Cell Physio/205: 328-34.

NATION, J.L. (1983). A new method using hexamethyldisilazane for preparation of soft insect tissues for scanning electron microscopy. Stain Techno/58: 347-51.

ODOR, D.L. and BLANDAU, R.J. (1956). Incidence of polyspermy in normal and delayed matings in rats of the Wistar strain. Fertil Steril7: 456-467.

PARK, K.S., SONG, H.B. and CHUN, S.S. (2000). Late fertilization of unfertilized human oocytes in in vitro fertilization and intracytoplasmic sperm injection cycles: conventional insemination versus ICSI. J. Assist. Reprod. Genet. 17: 419-24.

PHILLIPS, D.M. and SHALGI, R. (1982). Sperm penetration into rat ova fertilized in vivo. J. Exp. Zool. 221: 373-378.

SAMMONS, R. and MARQUIS, P. (1997). Application of the low vacuum scanning electron microscope to the study of biomaterials and mammalian cells. Biomaterials 18: 81-6.

SATHANANTHAN, A.H. (1994). Ultrastructural changes during meiotic maturation in mammalian oocytes: unique aspects of the human oocyte. Microsc Res Tech 27: $145-64$.

SENGOKU, K., TAMATE, K., HORIKAWA, M., TAKAOKA, Y., ISHIKAWA, M. and DUKELOW, W.R. (1995). Plasma membrane block to polyspermy in human oocytes and preimplantation embryos. J. Reprod. Fertil. 105: 85-90.

SHALGI, R. and KRAICER, P.F. (1978). Timing of sperm transport, sperm penetration and cleavage in the rat. $J$ Exp Zoo/204: 353-60.

SHALGI, R. and PHILLIPS, D.M. (1980). Mechanics of in vitro fertilization in the hamster. Biol Reprod 23: 433-344.

SIMERLY, C.R., HECHT, N.B., GOLDBERG, E. and SCHATTEN, G. (1993). Tracing the incorporation of the sperm tail in the mouse zygote and early embryo using an anti-testicular alpha-tubulin antibody. Dev Bio/158: 536-548.

SLIZOVA, D., KRS, O. and POSPISILOVA, B. (2003). Alternative method of rapid drying vascular specimens for scanning electron microscopy. J Endovasc Ther 10: $285-7$.

STOKES, D.J. (2003). Recent advances in electron imaging, image interpretation and applications: environmental scanning electron microscopy. Philos Transact A Math Phys Eng Sci361: 2771-87.

SZOLLOSI, D. (1965). The fate of sperm middle-piece mitochondira in the rat egg. J. Exp. Zool. 159: 367-377.

SZOLLOSI, D. (1971). Morphological changes in mouse eggs due to aging in the fallopian tube. Am J Anat 130: 209-25.

SZOLLOSI, D. and HUNTER, R.H. (1973). Ultrastructural aspects of fertilization in the domestic pig: sperm penetration and pronucleus formation. JAnat116:181206.

TAKAHASHI, T., SAITO, H., HIROI, M., DOI, K. and TAKAHASHI, E. (2000). Effects of aging on inositol 1,4,5-triphosphate-induced $\mathrm{Ca}(2+)$ release in unfertilized mouse oocytes. Mol Reprod Dev 55: 299-306.
TALBOT, P. and CHACON, R.S. (1982). Ultrastructural observations on binding and membrane fusion between human sperm and zona pellucida-free hamster oocytes. Fertil. Steril. 37: 240-248.

TARIN, J.J., PEREZ-ALBALA, S. and CANO, A. (2000). Consequences on offspring of abnormal function in ageing gametes. Hum Reprod Update 6: 532-49.

THIEL, B.L. and TOTH, M. (2005). Secondary electron contrast in low-vacuum/ environmental scanning electron microscopy of dielectrics. J. Appl. Phys. 97:118.

UBERO-PASCAL, N., FORTUNO, J.M. and DE LOS ANGELES PUIG, M. (2005). New application of air-drying techniques for studying Ephemeroptera and Plecoptera eggs by scanning electron microscopy. Microsc Res Tech68: 26471.

VON WEYMARN, N., GUGGENHEIM, R. and MULLER, H. (1980). Surface characteristics of oocytes from juvenile mice as observed in the scanning electron microscope. Anat.Embryol.(Berl). 161: 19-27.

WEBB, M., HOWLETT, S.K. and MARO, B. (1986). Parthenogenesis and cytoskeletal organization in ageing mouse eggs. J.Embryol.Exp.Morphol. 95: 131-45.

WILCOX, A.J., WEINBERG, C.R. and BAIRD, D.D. (1998). Post-ovulatory ageing of the human oocyte and embryo failure. Hum Reprod 13: 394-7.

WOLF, D.P. (1978). The block to sperm penetration in zona-free mouse eggs. Dev. Biol. 64: 1-10.

WOLF, D.P. and HAMADA, M. (1976). Age-dependent losses in the penetrability of mouse eggs. J. Reprod. Fert. 48: 213-214.

WOLF, D.P., NICOSIA, S.V. and HAMADA, M. (1979). Premature cortical granule loss does not prevent sperm penetration of mouse eggs. Dev. Biol. 71: 22-32.

WORTZMAN, G.B. and EVANS, J.P. (2005). Membrane and cortical abnormalities in post-ovulatory aged eggs: analysis of fertilizability and establishment of the membrane block to polyspermy. Mol Hum Reprod 11: 1-9.

WORTZMAN-SHOW, G.B., KUROKAWA, M., FISSORE, R.A. and EVANS, J.P. (2007). Calcium and sperm components in the establishment of the membrane block to polyspermy: studies of ICSI and activation with sperm factor. Mol. Human Reprod. 13: 557-565.

XU, Z., ABBOTT, A., KOPF, G.S., SCHULTZ, R.M. and DUCIBELLA, T. (1997). Spontaneous activation of ovulated mouse eggs: Time-dependent effects on $\mathrm{M}$ phase exit, cortical granule exocytosis, maternal messenger ribonucleic acid recruitment, and inositol 1,4,5-trisphosphate sensitivity. Biol.Reprod. 57: 743750.

YANAGIMACHI, R. and NODA, Y.D. (1970). Electron microscope studies of sperm incorporation into the golden hamster egg. Am J Anat. 128: 429-462.

YANAGIMACHI, R. (1978). Sperm-egg association in mammals. Curr Top Dev Biol. 12: 83-105.

YANAGIMACHI, R. (1994). Mammalian fertilization. In The Physiology of Reproduction, (ed. KNOBIL, E. and NEILL, J. D.). Raven Press, Ltd., New York, pp.189-317.

YANAGIMACHI, R. and CHANG, M.C. (1961). Fertilizable life of golden hamster ova and their morphological changes at the time of losing fertilizability. $J$ Exp Zool147: 185-197.

YUZPE, A.A., LIU, Z. and FLUKER, M.R. (2000). Rescue intracytoplasmic sperm injection (ICSI)-salvaging in vitro fertilization (IVF) cycles after total or near-total fertilization failure. Fertil Steri/73: 1115-9.

ZUCCOTTI, M., YANAGIMACHI, R. and YANAGIMACHI, H. (1991). The ability of hamster oolemma to fuse with spermatozoa: Its acquisition during oogenesis and loss after fertilization. Development 112: 143-152. 


\section{Related, previously published Int. J. Dev. Biol. articles}

See our recent Special Issue Developmental Biology in Poland edited by Tarkowski, Maleszewski and Kloc at: http://www.ijdb.ehu.es/web/contents.php?vol=52\&issue=2-3

See our recent Special Issue Ear Development edited by Fernando Giraldez and Bernd Fritzsch at:

http://www.ijdb.ehu.es/web/contents.php?vol=51\&issue=6-7

Mammalian fertilization:the egg's multifunctional zona pellucida

Paul M. Wassarman and Eveline S. Litscher

Int. J. Dev. Biol. (2008) 52: 665-676

Regionalized calcium signaling in zebrafish fertilization

Dipika Sharma and William H. Kinsey

Int. J. Dev. Biol. (2008) 52: 561-570

Defective calcium release during in vitro fertilization of maturing oocytes of LT/Sv mice

Karolina Archacka, Anna Ajduk, Pawel Pomorski, Katarzyna Szczepanska, Marek Maleszewski and Maria A. Ciemerych

Int. J. Dev. Biol. (2008) 52: doi: 10.1387/ijdb.072397ka

Association of egg zona pellucida glycoprotein mZP3 with sperm protein sp56 during fertilization in mice.

$\mathrm{N}$ Cohen and $\mathrm{P} M$ Wassarman

Int. J. Dev. Biol. (2001) 45: 569-576

2006 ISI **Impact Factor $=3.577^{* *}$

Fertilization triggers activation of Fyn kinase in the zebrafish egg.

W Wu and W H Kinsey

Int. J. Dev. Biol. (2000) 44: 837-841

Mechanisms of initiation and propagation of the calcium wave during fertilization in deuterostomes.

F Berger

Int. J. Dev. Biol. (1993) 37: 245-262

Review of scientific contributions by the Belgian medical centers concerned with human in vitro fertilization and embryo transfer (IVF).

$Y$ Englert and $\mathrm{M}$ Van den Bergh

Int. J. Dev. Biol. (1992) 36: 197-204

Cytoskeleton organization during oogenesis, fertilization and preimplantation development of the mouse.

B Maro, J Kubiak, C Gueth, H De Pennart, E Houliston, M Weber, C Antony and J Aghion

Int. J. Dev. Biol. (1990) 34: 127-137

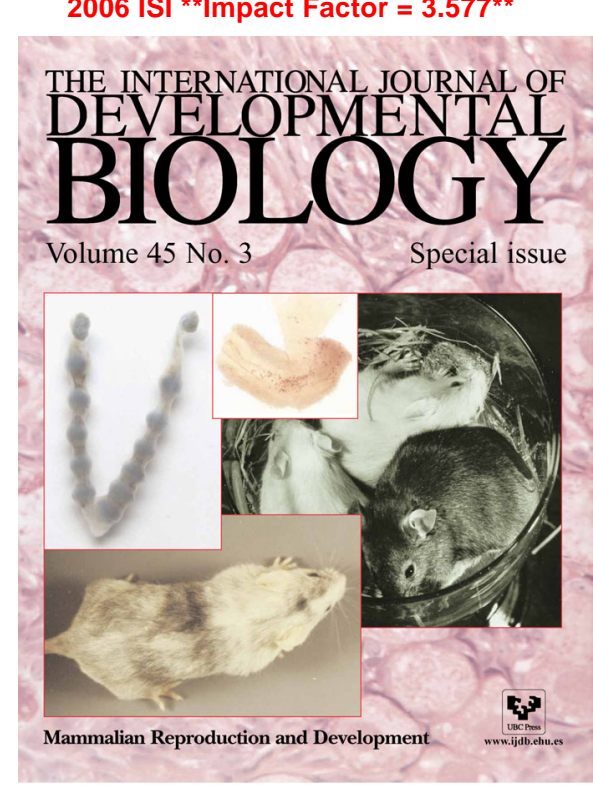

